\title{
O IMPOSSÍVEL EQUILÍBRIO ENTRE OS PODERES E A JUdicialização DA POLÍTICA
}

The impossible balance between powers and the judicialization of politics

Newton Bignotto *

Resumo: $\mathrm{O}$ artigo trata do problema da judicialização da política e de sua relação com as teorias modernas da separação dos poderes e dos mecanismos de equilíbrio institucionais, que asseguram a duração dos regimes políticos livres. À luz de alguns artigos dos Federalistas procuramos explorar os limites das teorias citadas e os riscos que os corpos políticos correm ao não levar em conta o caráter faccioso das relações políticas presentes em todos os regimes políticos. Ao longo do artigo procuramos dar atenção ao caso brasileiro atual no qual o Poder Judiciário tem desempenhado um papel de protagonista na vida política do país.

Palavras-chave: Democracia. Poder judiciário. Balança de poderes. Judicialização da política.

Abstract: The article deals with the problem of the judicialization of politics and its relation to modern theories of the separation of powers and mechanisms of institutional equilibrium that ensure the duration of free political regimes. In the light of some Federalists' articles, we seek to explore the limits of these theories and the risks that political bodies face in failing to take account of the partisan character of political relationships present in all political regimes. Throughout the article we seek to give attention to the current Brazilian case in which the Judiciary has played a leading role in the political life of the country. Key-words: Democracy. Judiciary Power. Balance of Powers. Judicialization of Politics.

\footnotetext{
* Professor titular do Departamento de Filosofia da Universidade Federal de Minas Gerais.
} Artigo recebido em 05/11/2018 e aprovado para publicação em 15/11/2018. 
debate sobre o que se convencionou chamar de judicialização da política é relativamente recente no Brasil, embora já faça parte dos horizontes da filosofia política e da filosofia do direito há um bom tempo. A razão mais provável para o aparecimento tardio da questão entre nós é a história constitucional do país. Até a Constituição de 1988, a relação entre o poder judiciário e os outros poderes era de tal maneira marcada pela conjuntura política, que seria difícil abordar um tema que em sua formulação mais imediata exige a separação dos poderes consolidada em uma dimensão mais ampla do que a letra dos textos legais em vigor. A esse respeito, basta lembrar a incômoda posição de submissão do judiciário brasileiro, em particular de seu órgão maior, o Supremo Tribunal Federal, durante o período da Ditadura militar, para nos darmos conta de que não fazia sentido discutir o tema, quando a existência de uma constituição legítima estava em questão e quando o poder executivo não deixava margens para a contestação de suas decisões. ${ }^{1}$

O panorama da relação entre os poderes da república muda radicalmente a partir de 1988. No final da década dos 90 começam a aparecer os primeiros estudos que levam em conta a nova realidade política e jurídica do país. ${ }^{2}$ Alguns analistas observaram que a nova Constituição permitiu o aparecimento de um pensamento jurídico, que se afastava do positivismo, que tinha sido hegemônico no quadro do pensamento e da prática judicial brasileira. ${ }^{3}$ Nessa nova situação, a interpretação do texto constitucional e as práticas decorrentes de leituras alargadas dele expandiram notavelmente os horizontes do direito brasileiro forjando o que muitos pesquisadores viriam a pensar como uma nova era na vida política nacional. "Em outras palavras- resume Cittadino- a abertura constitucional permite que cidadãos, partidos políticos, associações etc. integrem o círculo de intérpretes da Constituição, democratizando o processo interpretativo - na medida em que ele se torna aberto e público - e, ao mesmo tempo, concretizando a Constituição".

Os estudos sobre a nova realidade constitucional se debruçavam sobre dois temas. O primeiro, conectado com o debate internacional, colocava a questão da natureza dos processos de judicialização no centro de suas preocupações procurando compreender as raízes do problema e suas consequências de longo prazo. O segundo tema, que não era pensado à distância do primeiro, mas como sua continuação, focava no que se chamava genericamente de "ativismo judicial", processo que parecia mudar a

\footnotetext{
${ }^{1}$ A esse respeito ver: RECONDO, Felipe. Tanques e Togas. O STF e a Ditadura Militar. São Paulo: Companhia das Letras, 2018.

${ }^{2}$ WERNECK VIANNA, Luiz (et al.). A judicialização da política e das relações sociais no Brasil. Rio de Janeiro: Editora REVAN, 1999.

${ }^{3}$ CITTADINO, Gisele. Judicialização da Política, Constitucionalismo Democrático e separação dos poderes. In: WERNECK VIANNA, Luiz. A Democracia e o três poderes no Brasil. Belo Horizonte: Editora da UFMG, 2002.

${ }^{4}$ Idem, p. 31.
} 
face da vida política e jurídica do país. Num primeiro momento, a crença de que a democracia brasileira começara a viver um ciclo virtuoso fez com que a maior presença do poder judiciário na cena pública fosse vista como algo positivo, que encaminhava o Brasil para uma situação que já era vivida por outros países, os Estados Unidos em particular, há muito tempo. ${ }^{5}$ A presença de juízes e, numa escala crescente, de promotores de justiça na arena pública, influenciando processos de decisão, que nas décadas anteriores haviam sido dominados pelo poder executivo, ou no limite pelo poder legislativo, parecia prefigurar uma alteração da balança dos poderes em favor de uma interpretação mais democrática da tarefa de interpretação e concretização da Constituição. A união entre a vontade popular e poder judiciário era vista como um mecanismo capaz de atuar como "regente republicano das liberdades positivas". ${ }^{6}$

Em suma, o ativismo judicial, que desaguava no processo de judicialização, era visto como uma expansão da soberania popular. Quanto mais a interpretação da Constituição fosse efetivada por grupos amplos e abertos da sociedade maiores seriam as chances de que seu caráter democrático se consolidasse em práticas e regulações abertas a um número cada vez mais expressivo de cidadãos e de representantes da sociedade civil. Nesse momento inicial de alteração na maneira como a Constituição era vivida pela sociedade, a preocupação maior era a de saber se a democratização da comunidade de intérpretes não comportava riscos que poderiam potencialmente colocar em perigo o que havia sido alcançado com o texto de 1988.

Giselle Cittadino, que se inscrevia no campo dos que saudavam a judicialização da política como algo bom, parecia antever dois perigos. De um lado, dizia ela; "o que nos resta é perguntar se o vínculo entre ativismo judicial e reforço da lógica democrática que subjaz ao processo de judicialização da política pode viabilizar essa quebra de limites normativos à soberania popular, por mais legítimo que seja o movimento político a dar-lhe sustentação". ${ }^{7}$ Do outro lado, em tom otimista, ela acreditava que: "o processo de judicialização da política não precisa invocar o domínio dos tribunais, nem defender uma ação paternalista por parte do Poder Judiciário". 8

Os anos que se seguiram às constatações da estudiosa, e de muitos outros pensadores que no final da década dos 90 se dedicaram ao tema, acaba-

\footnotetext{
${ }^{5}$ Essa, por exemplo, era a posição de José Eisenberg que no final de um texto consagrado ao problema afirmava: "Essa politização do nosso Judiciário é para o bem, ainda que muitas vezes possa ser também para o mal, mas não faltam exemplos de como nosso direito vem funcionando no Brasil como contrapeso radical a práticas conservadoras da classe política ou econômica". EISENBERG, José. Pragmatismo, Direito Reflexivo e Judicialização da Política. In: WERNECK VIANNA, Luiz. A Democracia e o três poderes no Brasil. p. 59.

${ }^{6}$ CITTADINO, Gisele. Judicialização da Política, Constitucionalismo Democrático e separação dos poderes, p. 34 .

7 Idem, p. 37.

${ }^{8}$ Idem, p. 39.
} 
ram por inverter a ordem de preocupações com os riscos da judicialização da política. O perigo de que a extensão das reivindicações políticas em nome da soberania do popular pudesse fragilizar a ordem constitucional em nome de um processo contínuo de revisão do texto constitucional se mostrou infundado. Por outro lado, a tutela da vida politica pelo Poder Judiciário e a contínua modificação da Constituição por imposição de grupos políticos que nem de longe representavam o elemento popular da cidadania, mostrou-se uma verdadeira ameaça para a consolidação da democracia brasileira, embora esteja longe de ser a única. Ao falarmos hoje de judicialização da política estamos nos referindo ao fato de que cada vez mais as disputas entre partes da sociedade e mesmo entre indivíduos encontra seu fórum definitivo nos órgãos do judiciário. Se de um lado é evidente que esse poder tem a vocação de dirimir disputas entre entes particulares do corpo político, chama a atenção o fato de que as disputas internas do Poder Legislativo passaram a convergir para a magistratura superior, mas também que a vida administrativa do aparato do Estado brasileiro passou a ser pautada por indicações de procuradores e promotores, que muitas vezes atuam em franjas do direito que, a priori, escapam às suas competências. De forma ainda mais radical, quando pensamos na questão da interpretação da Constituição, órgãos como o STF deixaram de reivindicar o lugar de intérprete privilegiado do texto maior, para se atribuírem o papel do legislador, quando lhes pareceu que a lei devia ser criada ou modificada segundo princípios que nem sempre correspondem ao espírito do texto de 1988. Trinta anos depois da nova Constituição, os cientistas políticos continuam a se preocupar com o fenômeno sem muitas vezes atentar para o tamanho dos riscos que ele representa para a vida democrática. ${ }^{9}$ A constatação dos excessos não tem levado á conclusão de que o poder judiciário pode contribuir para o colapso do texto constitucional que deveria defender.

De maneira resumida, é no ambiente de uma presença cada vez mais invasiva do Poder Judiciário em amplos domínios de nossa vida em comum que a questão da judicialização da política se coloca hoje no Brasil.

Seria impossível tratar no espaço de um texto de todos as dimensões do tema que nos interessa. A complexidade da questão é tal que se define melhor como uma área de pesquisa do que como o objeto de um artigo. Por isso, é preciso renunciar à pretensão da completude e focar a atenção em uns poucos pontos, mesmo sabendo que com isso alcançaremos resultados parciais e modestos. Antes, no entanto, de explicitar nossos

\footnotetext{
${ }^{9}$ Essa é a posição, por exemplo, de Sérgio Abranches que no interior de considerações lúcidas sobre o funcionamento do sistema político brasileiro mostra que o poder judiciário tem exorbitado de suas funções, sem concluir, no entanto, que esses atos podem destruir a própria Constituição. ABRANCHES, Sérgio. Presidencialismo de Coalizão. Raízes e Evolução do Modelo Político Brasileiro. São Paulo: Companhia das Letras, 2018, p. 363-368.
} 
objetivos principais e nossas hipóteses teóricas, é preciso circunscrever o campo conceitual no qual nos situamos. Em outras palavras, devemos primeiro definir o que estamos entendendo por judicialização da política, para depois seguir adiante.

Partilhamos nosso ponto de partida com outros pesquisadores brasileiros. Tomando os trabalhos de Vallinder ${ }^{10}$ como referência, é possível afirmar que a judicialização é o processo de "infusão de processos decisórios jurídicos e de procedimentos típicos de tribunais nas arenas políticas onde estes processos e procedimentos não se faziam presentes". ${ }^{11}$ Como observa Eisenberg, esse processo implica tanto a politização do judiciário, quando esse poder se põe a legislar transferindo poderes típicos do Executivo e do Legislativo para os juízes; quanto a "tribunalizacão da política", quando os métodos típicos do Poder Judiciário começam a ser empregados pelos outros poderes. ${ }^{12} \mathrm{O}$ fenômeno assim descrito impactou vários campos de estudos e fez surgir muitas perguntas. No campo da filosofia do direito autores como Habermas tenderam a pensar que a judicialização expressa a necessidade de recuperação do "sentido original da soberania popular"; enquanto para Dworkin o fenômeno assinala a defesa de "uma ordem jurídica formada por direitos constituídos e compartilhados por todos os cidadãos" ${ }^{13}$ No campo da filosofia política, segundo Avritzer, as investigações "tem sua origem tanto na obra de Montesquieu quanto no próprio processo de implementação da Constituição dos Estados Unidos, no qual o principal objetivo dos fundadores constituiu o estabelecimento do governo misto". ${ }^{14}$

Nossas interrogações se situam nesse segundo campo.

\section{O controle de constitucionalidade}

Um grande número de intérpretes atribui ao caso Marbury vs Madison de 1803 nos Estados Unidos o nascimento do debate contemporâneo sobre o controle de constitucionalidade, que estaria na origem da extensão do poder judiciário a domínios da vida política que antes lhe escapavam. A questão que deveria ser decidia pelo juiz Marshall era a de saber a quem

\footnotetext{
${ }^{10}$ VALLINDER, Torbjörn, When the Courts Go Marching In: In The Global Expansion of Judicial Power. New York: New York University Press, 1995.

${ }^{11}$ Idem, p. 13. Apud EISENBERG, José. Pragmatismo, Direito Reflexivo e Judicialização da Política, p. 47.

${ }^{12}$ Idem, p. 47. A esse respeito ver também: AVRITZER, Leonardo. Judicialização da política e equilíbrio de poderes no Brasil. In: Leonardo Avritzer; Newton Bignotto; Fernando Filgueiras Juarez Guimarães, Heloísa Starling. Dimensões Políticas da Justiça. Rio de Janeiro: Civilização Brasileira, 2013, p. 215.

${ }^{13}$ EISENBERG, José. Pragmatismo, Direito Reflexivo e Judicialização da Política, p. 45.

${ }^{14}$ AVRITZER, Leonardo. Judicialização da política e equilíbrio de poderes no Brasil, p. 216.
} 
cabia o poder de controlar a constitucionalidade dos atos dos diversos poderes. Numa vertente que ainda hoje é influente, o controle de constitucionalidade era pensado como uma ação difusa, que fazia de cada juiz um intérprete da Constituição em cada um de seus atos. Para essa corrente de pensamento, não há um órgão central que detenha o poder indisputável de decisão sobre o conteúdo da Constituição e sua significação. Como veremos essa era a posição de alguns dos Federalistas. No caso referido, Marshall vai na direção contrária e afirma que o fato de que a Corte Suprema não foi eleita não quer dizer que ela não detenha o poder necessário para interpretar a Constituição sempre que ela parecer ameaçada por ações particulares dos diversos atores da arena pública. Nas palavras de Bruce Ackerman, se referindo à decisão do juiz do caso de 1803: "Ele afirma que a Constituição, enquanto lei suprema, possui um status superior em virtude do fato de que foi adotada pelo povo ele mesmo. Enquanto um movimento constitucional não conseguiu emendar nossa lei suprema, a tarefa da Corte é a de preservar os julgamentos do povo contra toda erosão ocasionada pelo processo ordinário de legislação". ${ }^{15}$

Essa decisão esteve longe de se impor de maneira definitiva e, de certa maneira, continua até hoje a provocar controvérsias nos Estados Unidos e em outros países nos quais existe uma corte superior que ocupa um lugar de destaque na estrutura dos poderes republicanos. Mas não é isso que nos interessa aqui. Para nós, o relevante é o fato de que na discussão sobre o papel do poder judiciário nas sociedades contemporâneas a temática do controle de constitucionalidade ocupa um lugar central e influencia o debate sobre a judicialização da política. A razão pela qual essa disputa é importante está ligada ao fato de que boa parte das teorias políticas da contemporaneidade toma por referência duas formulações axiais da modernidade: a teoria da separação dos poderes e a ideia de que um bom governo depende do equilíbrio entre os poderes que o constituem. Bernard Manin já observou que, mesmo quando estudamos os temas no interior do debate entre Federalistas e Anti-federalistas na Revolução americana, é preciso ficar atento para a diferença entre as duas teorias. Enquanto a teoria pura da separação dos poderes aponta para a especialização funcional de cada poder; a teoria dos pesos e contrapesos exige que os poderes sejam repartidos para que nenhum deles possa abusar das prerrogativas que a Constituição lhes concede. ${ }^{16}$

Kelsen, que tinha restrições quanto a interpretação estrita da primeira teoria, dá dela uma formulação lapidar: "O conceito de separação de poderes

\footnotetext{
${ }^{15}$ ACKERMAN, Bruce. Au nom du peuple. Les fondements de la démocratie américaine. Paris: Calmann-Lévy, 1998, p. 110.

${ }^{16}$ MANIN, Bernard. Frontières, freins et contrepoids : la séparation des pouvoirs dans le débat constitutionnel américain de 1787. In: Revue française de science politique, 44e année, n², 1994, p. 260.
} 
designa um princípio de organização política. Ele pressupõe que os chamados três poderes podem ser determinados como três funções distintas e coordenadas do Estado, e que é possível definir fronteiras separando cada uma dessas três funções" ${ }^{17}$ Aceito esse quadro geral, o bom governo deve necessariamente manter o equilíbrio interno e, para isso, precisa de mecanismos de controle e contrapesos, que se tornou conhecido na literatura política como a teoria dos checks and balances. Esses controles são necessários porque, como já observava Kelsen: "A significação histórica do princípio chamado separação de poderes encontra-se precisamente no fato de que ele opera antes contra uma concentração que a favor de uma separação de poderes". ${ }^{18}$ Diante, portanto, da adoção por órgãos do executivo de procedimentos típicos do judiciário, que chamamos hoje de judicialização da política, torna-se necessário pensar procedimentos que evitem riscos para a democracia equilibrando as ações dos diversos domínios de poder. É nesse quadro teórico referencial que muitos pensadores contemporâneos tentam avaliar os riscos inerentes aos processos que estamos analisando.

Nossa hipótese nesse texto é a de que, se as referências teóricas mencionadas são uma baliza importante para compreender a natureza do fenômeno referido, elas não nos permitem avaliar os perigos que rondam as sociedades nas quais um dos poderes se torna dominante. Para uma boa parte das ciências políticas, sobretudo norte-americanas, o problema é o do equilíbrio entre partes do governo. Com os devidos mecanismos de pesos e contrapesos é possível limitar e até mesmo eliminar as ameaças surgidas pelo que pode ser caracterizado como quebra da regra de balanceamento das forças que compõe um Estado de Direito. Ora, parece-nos que essa abordagem do problema dá conta do tema na esfera da administração governativa, mas é incapaz de lidar com o fato de que em determinadas situações é a sobrevivência do corpo político que está em jogo, sua dissolução enquanto unidade política, e não apenas uma mudança interna aos governos sucessivos. Em particular, acreditamos que os riscos que os excessos do poder judiciário fazem correr aos regimes livres têm sido subestimados por toda uma tradição do pensamento político moderno.

A segunda hipótese desse texto é que a concepção mecânica de governo herdada da modernidade obnubilou o fato de que pensadores como Montesquieu e alguns dos Federalistas já anteviam que a morte de um corpo político pode ser o resultado de processos internos, que nem sempre são tão radicais quanto as revoluções, mas que pode estar ligada à degradação cotidiana da estrutura de governo. Nesse sentido, acreditamos que o pensador francês e seus herdeiros americanos oferecem referenciais teóricos bem mais abertos do que aqueles fundados nas teorias mencionadas acima

${ }^{17}$ KELSEN, Hans. Teoria geral do Direito e do Estado. São Paulo: Martins Fontes, 2000, p. 385.

${ }^{18}$ Idem, p. 402. 
para pensar fenômenos como o da judicialização da política. Nosso propósito é o de mostrar como nossas duas hipóteses convergem e oferecem um quadro sombrio das possibilidades de destruição dos regimes a partir dos desequilíbrios internos da divisão dos poderes.

Como desejamos explorar uma tradição de pensamento que possui várias camadas, para restringirmos a extensão de nossas análises, vamos nos fixar nos pensadores americanos, que lidavam com o problema prático de fundar e estabilizar uma nova forma de governo, baseada numa Constituição, que representava uma inovação na história política ocidental. Secundariamente vamos nos ocupar com alguns argumentos de Montesquieu que influenciaram diretamente o pensamento dos Federalistas.

\section{Os Federalistas e as facções}

No curso dos anos de criação dos Estados Unidos é natural que as discussões levadas a cabo pelos fundadores da nação respondessem muito mais a imperativos práticos do que ao desejo de expor teorias e seus vínculos com o passado. ${ }^{19}$ Isso não quer dizer que eles não reconhecessem e usassem as filosofias do passado em suas reflexões e como base de suas ações. No tocante ao problema da separação dos poderes, Montesquieu era a referência mais forte, embora não a única, e a mais constante nos debates que antecederam a adoção da Constituição e nas polêmicas que se seguiriam ao ato de fundação do novo corpo político. ${ }^{20}$ É nos textos dos Federalistas que encontramos os conceitos necessários para tentar demonstrar a plausibilidade de nossas hipóteses.

Alguns artigos chamam nossa atenção. O primeiro, o de número dez, é assinado por Madison e trata da questão das facções na vida pública. $\mathrm{O}$ segundo, o de número 78, é assinado por Hamilton, e trata das funções dos juízes e do poder judiciário no interior de uma democracia. Em terceiro lugar, os artigos 47 a 51 abordam diretamente o tema da separação dos poderes e sua estrutura interna. ${ }^{21}$ No corpo do livro esses artigos não estão diretamente associados, mas é possível mostrar que, lendo-os em conjunto, eles nos ajudam a esclarecer aspectos essenciais da questão que estamos tratando.

\footnotetext{
${ }^{19}$ STARLING, Heloísa. A Matriz Americana. In: BIGNOTTO, Newton (org). Matrizes do Republicanismo. Belo Horizonte: Editora da UFMG, 2013.

${ }^{20}$ A esse respeito ver: MCDONALD, Forrest. Novus Ordo Seclorum. The Intellectual Origins of the Constitution. Lawrence: The University Press of Kansas, 1985; BAILYN, Bernard. The Ideological Origins of the American Revolution. Cambridge: Harvard University press, 1992.

${ }^{21}$ HAMILTON, MADISON, JAY. The Federalist Papers. New York: New American Library, 1961.
} 
No primeiro deles, Madison se lança no estudo dos efeitos provocados na vida pública pela atuação do que chama de facções. Na época em que escrevia esse era um problema central para os americanos, que lutavam para impor uma visão dominante da futura organização institucional do país. Havia uma queixa generalizada entre os cidadãos de que as diversas facções tornavam a vida política instável e arriscada ameaçando com frequência os direitos dos estratos minoritários da sociedade. ${ }^{22}$ Madison definia uma facção como "um conjunto de cidadãos, quer formem uma maioria ou a minoria do todo, que são unidos e agem movidos por algum impulso comum da paixão ou pelo interesse contrário aos direitos dos outros cidadãos, ou ao interesse constante e geral da comunidade" ${ }^{23}$ Esse é um tema clássico do pensamento político ocidental. Ele encontra no ambiente moderno uma significação nova na medida em que os grupos facciosos são vistos como uma ameaça ao núcleo da soberania popular e sua expressão no interesse comum. Ackerman, trazendo as análises dos Federalistas para a linguagem atual, diz-nos que podemos falar de dois tipos de facção: as "ideológicas" ou "carismáticas", baseadas nas paixões e aquelas fundadas nos interesses particulares. ${ }^{24}$ As primeiras são formadas por um movimento passional e, por isso, são, segundo o pensador, de menor duração. O segundo tipo tem seu fundamento nos interesses e são mais resistentes ao passar do tempo, pois refletem com precisão algumas das características mais essenciais da natureza humana. Nada impede que um grupo faccioso reúna os dois tipos em seu interior, mas a distinção é interessante por permitir-nos avaliar os riscos constantes que o predomínio da parte sobre o todo faz correr ao regime republicano.

Olhando para os dias de hoje, é possível avaliar o caráter quase premonitório que esse tratamento do tema iria alcançar. No caso das facções "ideológicas", elas parecem florescer não apenas no interior dos diversos extratos da sociedade, mas também no interior dos partidos e das instituições. A tempestade provocada pela adoção de ideologias particularistas no interior das sociedades contemporâneas mostra como o projeto de fazer valer uma determinada concepção da sociedade como se fosse um valor universal pode ser devastador. É claro que a primeira coisa que nos vem à mente, quando enunciamos essa hipótese, são os regimes totalitários. Mas é necessário recordar que a atuação desse tipo de facção na cena pública tem graus e nem sempre destrói de imediato a cena pública. Em qualquer caso, no entanto, sua existência no interior do corpo político desestabiliza o equilíbrio entre os poderes e ameaça a Constituição. O que talvez não estivesse previsto nos artigos dos Federalistas é a intensidade que a luta de facções iria alcançar no interior dos poderes constituídos.

${ }^{22}$ Idem, artigo 10, p. 77.

${ }^{23}$ Idem, artigo 10, p. 78.

${ }^{24}$ ACKERMAN, Bruce. Au nom du peuple. Les fondements de la démocratie américaine, p. 242. 
Para compreender a radicalização trazida pelo tempo no campo das disputas facciosas talvez seja necessário recordar que o segundo tipo de facção, fundado "sobre a diversidade e a desigualdade na distribuição da riqueza"25", tornou-se quase um elemento constitutivo das sociedades capitalistas. Olhando o quadro atual de nossas democracias, em particular daquelas que estão longe de terem se consolidado, é imperativo reconhecer que elas são atravessadas por disputas originadas na luta pela posse dos meios materiais e que muitas vezes disfarçam essa disputa com argumentos ideológicos, que nem por isso são menos facciosos. Essa combinação se torna ainda mais sulfurosa quando nos recordamos que nossas sociedades atuais, a brasileira em particular, convive com níveis de desigualdade ultrajantes. A atuação das facções constituídas pelos interesses afeta não apenas a vida institucional, o que já não é pouco, mas a existência de grandes grupos da população submetidos a condições materiais desastrosas.

Nosso objetivo não é o de avaliar em sua extensão os efeitos da luta de facções, mas sim de compreender como elas colocam em questão a existência de uma sociedade livre. Nessa direção, Madison se pergunta se não seria possível extirpar as facções da vida pública. Para isso, segundo ele, há dois métodos. O primeiro consiste em combater as causas destruindo a "liberdade essencial à sua existência". ${ }^{26} \mathrm{O}$ segundo, tão pernicioso quanto o primeiro seria "dar a todos os cidadãos as mesmas opiniões, as mesmas paixões $e$ os mesmos interesses". ${ }^{27}$ A outra via possível para combater as facções é atuar sobre seus efeitos. Desse ponto de vista, a discussão recai sobre as instituições e seu funcionamento cotidiano. Vamos centrar nossa atenção primeiramente nas ações que visam as causas do aparecimento das facções.

Como intui corretamente Madison, o combate do mal por meio da limitação pura e simples das paixões e da diferença entre os homens e mulheres significaria o desaparecimento da liberdade. A existência de facções no interior de um Estado é um fato corriqueiro nas democracias contemporâneas o que representa uma ameaça contínua à sua existência. Ora, se isso é verdade, podemos deduzir que os regimes democráticos são constantemente ameaçados pelo fantasma do despotismo, ou, deveríamos dizer na linguagem atual, pelos autoritarismos diversos e pelo totalitarismo. Longe, portanto, de ser um fenômeno da luta política ordinária, as facções atingem, por meio de suas reivindicações particularistas, o núcleo estruturante da soberania popular.

O caráter permanente da divisão da sociedade em facções pode ser encontrado em todas as sociedades. Madison tinha uma visão ainda mais alargada do problema, pois aliava à observação da realidade histórica uma

\footnotetext{
${ }^{25}$ HAMILTON, MADISON, JAY. The Federalist Papers. Artigo 10, p. 79.

${ }^{26}$ Idem, Artigo 10, p. 78.

${ }^{27}$ Idem, Artigo 10, p. 78.
} 
antropologia política, que não deixava dúvidas quanto à gravidade do problema. Para ele: "as causas da existência das facções encontram-se latentes na natureza humana e nós as vemos aparecer em todos os lugares em diferentes tipos de atividade, segundo as diferentes combinações das sociedades humanas". ${ }^{28}$ Essa constatação estava longe de ser uma singularidade de seu pensamento. Gordon Wood relembra que nas discussões sobre a natureza do poder em 1776, um dos participantes do debate sobre a futura Constituição em Maryland observa, na esteira de Montesquieu, que todos os homens adoram o poder e que, por isso, não podem ser detentores de grandes extensões do mesmo pois serão inevitavelmente levados a abusar. ${ }^{29}$

As facções são, desse ponto de vista, uma realidade inultrapassável tanto no plano fenomenológico quanto do ponto de vista da antropologia política. Nesse sentido, devem fazer parte de toda equação da vida política que pretenda apreender os movimentos de criação e destruição das formas políticas. É verdade que naquele momento, os debates sobre a vida pública e suas formas institucionais eram marcados pelo desejo de construção de uma nova nação fundada sobre pilares que seriam capazes de garantir a grande obra da liberdade e da igualdade entre os cidadãos. Isso não impede, no entanto, que à distância dos eventos históricos, que levaram à fundação da democracia moderna, sejamos sensíveis a aspectos pouco visitados dos fundamentos das ideias que presidiram a criação de uma das matrizes mais influentes do republicanismo moderno. Em particular, devemos atentar para o fato de que os poderes constituidores da experiência republicana podem em determinadas situações se comportar como facções. Se esse for o caso, e nos parece que essa é uma afirmação verdadeira à luz do que acabamos de expor, eles podem estar na origem do processo de corrupção e destruição do corpo político. Para ficar no terreno de nossas preocupações, nada indica que o poder judiciário não pudesse ele mesmo se transformar numa ameaça à sobrevivência da liberdade.

\section{Separação dos poderes e a mecânica das instituições}

Dizendo de outra maneira. Se as facções são parte da paisagem humana e ameaçam o corpo político, só restava aos Federalistas tentar contê-las insistindo na separação dos poderes. ${ }^{30}$ Como recorda Ackerman: "Seria mais seguro de conceber e de integrar ao sistema um mecanismo de segurança. Mesmo quando a luta de facções está a pleno vapor, a separação dos poderes pode

\footnotetext{
${ }^{28}$ Idem, artigo 10, p. 79.

${ }^{29}$ WOOD, Gordon. The Creation of the American Republic. 1776-1787. New York: W.W. Norton \& Company, 1969, p. 150.

${ }^{30}$ MANIN, Bernard. Frontières, freins et contrepoids : la séparation des pouvoirs dans le débat constitutionnel américain de 1787, p. 271.
} 
ter um papel modesto mas crucial. Cada órgão pode se opor aos movimentos facciosos dos outros". ${ }^{31}$ Esses temas aparecem nos artigos 47 a 51 e mostram como os homens da Revolução americana pensavam realizar a tarefa de oferecer ao corpo político uma estrutura que o tornasse mais resistente às tempestades, que não deixarão de ocorrer ao longo da história.

Madison aborda a questão referindo-se diretamente aos escritos de Montesquieu e tendo diante dos olhos dois fatos. O primeiro era a constatação de que nem todas as Constituições estaduais tinham sido elaboradas levando em conta, com o devido cuidado, o princípio da separação dos poderes. Isso se devia não apenas ao desconhecimento teórico da questão, mas, e esse era o segundo fato, que no curso das ações governamentais os poderes apareciam muito mais misturados do que aparentemente deveriam estar. A incapacidade de distinguir o problema da separação dos poderes daquele do equilíbrio entre suas forças, como já lembramos, acabava por obscurecer o entendimento de ambas as teorias. ${ }^{32}$ Quanto a Madison, ele pretendia se servir ao máximo da herança teórica que recolhia no passado, para mostrar que era possível partir do princípio formal da separação dos elementos constitutivos do Estado republicano para estabelecer um equilíbrio dinâmico entre as partes.

Nosso propósito não é o de seguir as nuançadas análises que o autor faz das dificuldades de se equilibrar os poderes e de como o uso dos mecanismos adequados era o único caminho possível para a construção de uma república livre. Nosso interesse é o de acompanhar o lugar que o poder judiciário ocupa nos argumentos defendidos pelos Federalistas em torno dos riscos que o Estado de Direito corre quando um dos poderes usurpa as prerrogativas dos outros. Como vimos, esse é um fato que não pode ser deixado de lado uma vez que encontra suas raízes na natureza humana e pode ser constatado pelo estudo cuidadoso tanto do presente quanto do passado dos regimes. Nesse sentido, não há razão para excluir nenhum dos três poderes da análise dos riscos que correm as repúblicas. Ao seguir, no entanto, a argumentação dos Federalistas a respeito do tema e mesmo aquelas de Montesquieu constatamos que há uma assimetria no tratamento de cada um dos poderes.

O pensador francês insiste sobre o fato de que: "O poder de julgar não deve ser outorgado a um senado permanente mas exercido por pessoas extraídas do corpo do povo num certo período do ano, de modo prescrito pela lei, para formar um tribunal que dure apenas o tempo necessário". ${ }^{33}$ Os americanos não podiam acompanhar inteiramente o filósofo no que toca ao caráter transitório das cortes, mas se alinhavam inteiramente a ele no que tange ao fato de que:

\footnotetext{
${ }^{31}$ ACKERMAN, Bruce. Au nom du peuple. Les fondements de la démocratie américaine. p. 246.

${ }^{32}$ HAMILTON, MADISON, JAY. The Federalist Papers. Artigo 47, p. 307-308.

${ }^{33}$ MONTESQUIEU. Do Espírito das Leis. São Paulo: Editora Abril, 1979, II, VI, p. 149.
} 
"Não haverá também liberdade se o poder de julgar não estiver separado do poder legislativo e do executivo". ${ }^{34}$ Para Madison esses princípios nem sempre tinham sido compreendidos corretamente pelos legisladores estaduais, mas não havia dúvida de que eram a base de todo regime livre.

Ao analisar o conflito entre os poderes e a necessidade de se introduzir mecanismos de equilíbrio entre eles, Madison não faz referência direta a uma afirmação de Montesquieu que nos parece essencial para desenvolver nossos argumentos. Com efeito, o filósofo francês depois de apontar para o caráter inamovível da separação dos poderes e para a necessidade de se criar mecanismos para evitar os ataques recíprocos, afirma sem meias medidas que: "Dos três poderes dos quais falamos, o de julgar é, de algum modo, nulo". ${ }^{35}$ Esse é um elemento importante que será retomado sucessivamente pelos pensadores de várias tradições e que contribui para a crença de que o poder judiciário é o que menos ameaça a sobrevivência do corpo político. Hamilton o retoma com todas as letras no artigo 78, quando estuda as atribuições do poder judiciário. Curiosamente, Carl Schmitt também deu uma formulação clara dessa ideia em seus escritos sobre a Constituição. Examinando a questão da separação dos poderes, ele afirma: "Contrariamente às outras atividades do Estado, o judiciário não é absolutamente capaz de influenciar e de invadir. Ele está submetido à lei e mesmo quando ele decide sobre a validade de uma lei ele não sai do domínio da pura normatividade, ele cria obstáculos, mas não manda. Ele não é um poder como os outros poderes. Esse é o sentido da expressão de Montesquieu quando diz que sua potência é nula". ${ }^{36}$

Na sequência dos artigos nos quais o tema da separação entre os poderes é analisado, as atribuições do poder judiciário são estudadas, mas nada, ou quase nada, é dito sobre o papel nefasto que ele pode ter num momento de crise dos mecanismos de regulação da vida republicana. No artigo 51, Madison faz referência ao fato de que os que exercem algum dos poderes devem poder recorrer a mecanismos de defesa contra os que ameaçam o equilíbrio constitucional. Em consonância com as análises do artigo 10, ele mistura as considerações sobre a dinâmica institucional com as afirmações sobre a natureza humana. Essa combinação obriga os Estados a criar freios para não serem destruídos pelo movimento de suas forças internas. "Os meios de defesa- diz o autor- devem ser, nesse caso como em todos os outros, proporcionais aos perigos do ataque. É necessário opor a ambição à ambição e os interesses do homem devem estar ligados àqueles da Constituição". ${ }^{37}$ Ao poder judiciário cabe frear os outros poderes, sobretudo quando eles se desviam da Constituição. Em outras palavras, é por meio do controle de constitucionalidade que ele contribui para manter o equilíbrio que garante a liberdade

\footnotetext{
${ }^{34}$ Idem, II, VI, p. 149.

${ }^{35}$ Idem, II, VI, p. 151.

36 SCHMITT, Carl. Théorie de la Constitution. Paris: PUF, 1993, p. 333.

${ }^{37}$ HAMILTON, MADISON, JAY. The Federalist Papers. Artigo 51, p. 321.
} 
dos cidadãos. Hamilton afirma no artigo 78: "Essa conclusão não supõe de forma alguma a superioridade do poder judiciário sobre o poder legislativo. Ela supõe somente que o poder do povo é superior aos dois e que quando a vontade da legislatura, expressa em suas leis, está em oposição com aquela do povo, declarada na Constituição, é a ele que os juízes devem obedecer e não à primeira". ${ }^{38}$

Bruce Ackerman se interroga, ao analisar essas afirmações, se não existe o risco das cortes abusarem do direito de interpretar a Constituição e contribuir assim para sua destruição. ${ }^{39}$ Apesar desse alerta, ele segue em outra direção, se apoiando numa parte importante do artigo 51 dos Federalistas, para tomar partido na disputa que surgia então em torno de quem deveria ter a prerrogativa de exercer o controle de constitucionalidade. Para ele, são os juízes, no exercício de suas funções, que devem atuar para defender as leis fundamentais de um país, contra os excessos dos poderes legislativo e executivo. Optando pela interpretação mais aberta do controle das leis, contra os que defendem as conclusões do juiz Marshall em 1803, ele adere à corrente dos que acreditam que essa maneira de abordar o problema é mais próxima dos princípios federalistas, que colocavam a soberania popular no centro dos regimes livres. Em que pese a justeza de suas observações, para se pensar o papel dos juízes na defesa da Constituição, talvez fosse o caso de lembrar as palavras de Hamilton: "Mas é fácil ver que é necessário aos juízes um grau de coragem raro para se conduzir como fieis defensores da Constituição quando os avanços do legislativo são encorajados por vozes dominantes da comunidade nacional". 40

É inegável que os textos Federalistas, assim como os escritos de Montesquieu, sustentam a leitura que se tornou dominante segundo a qual o poder judiciário por sua natureza é o mais fraco de todos, o menos capaz de usurpar as prerrogativas do legislativo e do executivo e que, por isso, é o mais apto a defender a Constituição contra seus inimigos e a servir de fiel da balança nas disputas que podem destruir o corpo político.

É possível, no entanto, caminhar em outra direção e fazer valer as considerações de ordem antropológica já mencionadas. Nesse caso, é preciso reconhecer que estamos mudando de registro e deixando de lado o debate sobre a mecânica institucional para centrar nossa atenção no problema dos fundamentos da vida política. Tudo se passa como se estivéssemos deixando de lado os caminhos explorados pelas ciências sociais e políticas contemporâneas para nos orientar por uma problemática típica da filosofia política, a saber, a pesquisa sobre os fundamentos do político.

Colocando-se desse ponto de vista, as seguidas advertências dos Federalistas sobre a natureza ambiciosa dos homens e seu apetite pelo poder, se casam

\footnotetext{
${ }^{38}$ Idem, HAMILTON artigo 78, p. 467-8

${ }^{39}$ ACKERMAN, Bruce. Au nom du peuple. Les fondements de la démocratie américaine. p. 247.

${ }^{40}$ HAMILTON, MADISON, JAY. The Federalist Papers. Artigo 78, p. 470.
} 
muito bem com a desconfiança de Montesquieu em relação a natureza humana, que o levaram a afirmar: "Quanto mais houver homens reunidos, tanto mais esses serão fúteis e sentirão nascer neles o desejo de se notabilizar por pequenas coisas". ${ }^{41}$ Ora, as instituições existem para conter os apetites e paixões. Da maneira como atuam sobre a natureza humana surgem os diversos regimes. Mas se estamos falando de algo anterior às leis, é possível deduzir que essas são constantemente ameaçadas pela pressão que os indivíduos exercem sobre o corpo político para realizar seus desejos. Nessa lógica, o sonho do equilíbrio perfeito entre os poderes, alcançado por meio de pesos e contrapesos, é uma ilusão que encontra seus limites nas características mais banais da natureza dos homens. Do ponto de vista da antropologia exposta por Montesquieu e pelos Federalistas, somos levados a concluir que é impossível se alcançar no tempo da história um equilíbrio entre as partes de um regime livre, mesmo com todos os cuidados institucionais. Como já afirmava Montesquieu: Assim como todas as coisas humanas têm um fim, O Estado ao qual nos referimos (a Inglaterra) perderá sua liberdade, perecerá". ${ }^{42}$ Do ponto de vista dos fundamentos dos regimes livres não temos, portanto, razão alguma para supor que o poder judiciário escapa às determinações naturais e não ameaça, como os outros poderes o equilíbrio das formas democráticas e republicanas de governo.

\section{Conclusão}

A doutrina da separação dos poderes com todas suas nuanças e a ideia de que o bom governo depende do equilíbrio entre suas instituições ocupa como sabemos um lugar central no pensamento político moderno. Procuramos mostrar que ela esconde certos riscos, que são inerentes aos regimes republicanos. Voltando ao ponto de partida desse texto, a saber, a questão da judicialização da política, é possível dizer que a crença na fraqueza inerente do poder judiciário, aliada ao desiderato de um corpo politico equilibrado em sua dinâmica interna, acaba por criar uma cortina de fumaça, que obnubila a percepção dos perigos que rondam as democracias, quando um de seus elementos assumem um protagonismo excessivo. Os pensadores institucionalistas estão atentos para os desvios provocados pela soberba do poder executivo e pela ação desequilibrada do poder legislativo, mas tendem a deixar nas sombras os efeitos do exercício do poder judiciário, quando ele transborda para além de suas fronteiras naturais. Tudo se passa como se o próprio poder, visto seu caráter supostamente neutro no equilíbrio das forças que compõem o Estado moderno, pudesse controlar a si mesmo. Isso se mostra, por exemplo, no caso brasileiro, no

${ }^{41}$ MONTESQUIEU. Do Espírito das Leis. I, VII, I, p. 99.

${ }^{42}$ Idem, p. II, XI, VI, p. 154. 
fato de que os órgãos de controle do judiciário são praticamente endógenos, mesmo quando admitem a presença de representantes de outros setores da sociedade em seu seio. Destinado a fazer cumprir as leis e no limite a interpretar a Constituição, esse poder se comporta como se sua ação tivesse uma outra fonte de legitimidade do que a soberania popular.

Ao escolher uma interpretação aberta das teorias mencionadas, abrimos as portas para uma leitura do fenômeno da judicialização da politica, que nos conduz a um terreno distante daquele frequentado pelos defensores otimistas do ativismo judicial. Ao reivindicar para si uma parte das prerrogativas dos poderes legislativo e executivo, o poder judiciário não apenas se coloca à distância do ponto de equilíbrio da balança entre os componentes da vida pública republicana, como assume-se como representante da soberania popular naquilo que ela tem como seu fundamento principal: a atribuição de escrever a Constituição. Se assumirmos, portanto, que não é possível alcançar o equilíbrio perfeito entre os poderes, somos levados a concluir que o avanço de qualquer um deles no espaço do soberano representa um grave risco para liberdade, como já anteviam os Federalistas americanos. A distância, no entanto, do discreto otimismo com o qual encaravam o exercício do poder judiciário nas fronteiras de suas atribuições, o controle de constitucionalidade em particular, somos levados a acreditar que ele apresenta um risco para a democracia tão grande quanto aquele gestado pelo crescimento desmesurado da força dos outros poderes no interior da vida republicana.

Esse parece ser o quadro atual das disputas facciosas que dominam a cena política atual de muitos países, a do Brasil em especial. Se é inegável que a Constituição de 1988 ofereceu freios institucionais capazes de evitar os excessos do poder executivo e mesmo legislativo deixou de lado os mecanismos de contenção dos excessos dos juízes e procuradores. $\mathrm{O}$ Supremo Tribunal Federal (STF), em particular, passou a ocupar um lugar de destaque na cena política, sobretudo depois que as lutas entre partidos e poderes dominou a vida pública brasileira. Em muitos casos, em nome do controle de constitucionalidade, esse órgão tomou o lugar do legislador e, de forma ainda mais radical, se sobrepôs ao soberano, permitindo-se interpretar e corrigir sua vontade. Longe, portanto, de ajudar a controlar as consequências da luta de facções, sejam elas institucionais, políticas, ou econômicas, ele passou a se comportar como uma delas reivindicando um poder para si que está longe do que foi previsto pela Constituição.

A separação dos poderes e o equilíbrio entre eles permanece sendo um ideal regulador de todo Estado democrático de direito. A compreensão meramente mecânica desse desiderato, típica de correntes influentes do chamado institucionalisno, obscurece, no entanto, o fato de que a exacerbação do papel de um dos poderes no interior do corpo político pode ser um caminho sem volta para sua destruição. Afirmando o papel regulador das 
doutrinas citadas, é preciso aceitar que nos Estados históricos, submetidos às lutas intestinas entre seus componentes e ao desejo presente em todos os homens e mulheres de expandir seu raio de ação, não é possível alcançar o equilíbrio entre os poderes mesmo nas situações mais cotidianas. Montesquieu não só tinha consciência desses perigos como acreditava que eles podiam destruir qualquer regime. Mesmo a Inglaterra com seu sistema de pesos e contrapesos estava sujeita a flutuações que acabariam por destruir seu engenhoso sistema de governo. Em seu tempo, o pensador enxergava nos excessos dos poderes legislativo e executivo o maior fator de risco para a corrupção do regime. Afinal, para ele, a corrupção das formas políticas era a corrupção de seus princípios, o que acontece quando o equilíbrio interno se rompe em proveito de uma das partes. Ora, nos últimos anos, assistimos em vários países a cena pública ser povoada por excessos vindos de todos os lados. De forma inédita entre nós, o poder judiciário passou a reivindicar, em nome de uma suposta missão de purificação da vida política, não apenas o controle de constitucionalidade, mas também a prerrogativa de reescrever a Constituição à revelia da vontade popular. É preciso reconhecer que esse não é um cenário totalmente inédito na cena democrática. Em vários lugares, as intervenções do judiciário no debate público têm feito parte do cotidiano das nações livres. Isso não quer dizer, no entanto, que não representem riscos para a conservação da liberdade. Em países com larga tradição autoritária esses perigos nos parecem ainda mais evidentes, como procuramos mostrar. Diante desse alerta, talvez seja o caso de concluir com Montesquieu: "Quem o diria! A própria virtude tem necessidades de limites". 43

\section{Referências bibliográficas}

ABRANCHES, Sérgio. Presidencialismo de Coalizão. Raízes e Evolução do Modelo Político Brasileiro. São Paulo: Companhia das Letras, 2018, p. 363-368.

ACKERMAN, Bruce. Au nom du peuple. Les fondements de la démocratie américaine. Paris: Calmann-Lévy, 1998. P. 110.

AVRITZER, Leonardo. Judicialização da política e equilíbrio de poderes no Brasil. In: Leonardo Avritzer; Newton Bignotto; Fernando Filgueiras Juarez Guimarães, Heloísa Starling. Dimensões Políticas da Justiça. Rio de Janeiro: Civilização Brasileira, 2013. P. 215.

BAILYN, Bernard. The Ideological Origins of the American Revolution. Cambridge: Harvard University press, 1992.

${ }^{43}$ MONTESQUIEU. Do Espírito das leis. II, IV, p. 148. 
CITTADINO, Gisele. Judicialização da Política, Constitucionalismo Democrático e separação dos poderes. In: Luiz Werneck Vianna. A Democracia e o três poderes no Brasil. Belo Horizonte: Editora da UFMG, 2002.

EISENBERG, José. Pragmatismo, Direito Reflexivo e Judicialização da Política. In: Luiz Werneck Vianna. A Democracia e o três poderes no Brasil. P. 59.

HAMILTON, MADISON, JAY. The Federalist Papers. New York: New American Library, 1961.

KELSEN, Hans. Teoria geral do Direito e do Estado. São Paulo: Martins Fontes, 2000.

MANIN, Bernard. Frontières, freins et contrepoids: la séparation des pouvoirs dans le débat constitutionnel américain de 1787. In: Revue française de science politique, 44e année, $\mathrm{n}^{\circ} 2,1994$.

MCDONALD, Forrest. Novus Ordo Seclorum. The Intellectual origins of the Constitution. Lawrence: The University Press of Kansas, 1985.

RECONDO, Felipe: Tanques e Togas. O STF e a Ditadura Militar. São Paulo: Companhia das Letras, 2018

STARLING, Heloísa. A Matriz Americana. In: Newton Bignotto (org). Matrizes do Republicanismo. Belo Horizonte: Editora da UFMG, 2013.

SCHMITT, Carl. Théorie de la Constitution. Paris: PUF, 1993

VALLINDER, Torbjörn, When the Courts Go Marching In: In The Global Expansion of Judicial Power. New York: New York University Press, 1995.

WERNECK VIANNA, Luiz (et al.). A judicialização da política e das relações sociais no Brasil. Rio de Janeiro: Editora REVAN, 1999.

WOOD, Gordon. The Creation of the American Republic. 1776-1787. New York: W.W. Norton \& Company, 1969, p. 150.

Endereço do Autor:

Rua dos Timbiras 1497, Apt 902

30140-061 Belo Horizonte - MG

bignotto@ufmg.br 